CASE REPORT

\title{
Management of Instrument Separation: A Case Series
}

\author{
Sangeetha Saji ${ }^{1}$, Praveena Geetha ${ }^{2}$, Radhakrishnan K Nair ${ }^{3}$, Nisha Kurup ${ }^{4}$
}

\begin{abstract}
Background: During routine endodontic therapy, a clinician may encounter many procedural errors which alter the course and outcome of treatment. One of the most frequent types of procedural error is instrument separation. A separated instrument prevents complete cleaning and shaping of the root canal. Hence, every attempt must be made to retrieve the broken instrument. The clinician has to evaluate the options of attempting retrieval, and bypassing or leaving the fragment as it is. There are various instrument retrieval kits and chairside techniques available for this purpose.

Case description: The present case series describes the management of a separated rotary file and a separated bur head from the root canals of mandibular second molar and maxillary canine, respectively. A 14-year-old female patient undergoing root canal treatment in relation to 47 had an accidental breakage of ProTaper gold F2 rotary file in the apical third of distal canal of 47. Attempts were made to retrieve the instrument with ultrasonically activated files under dental operating microscope and was successfully managed. A 47-year-old female patient undergoing root canal treatment in relation to $13 \mathrm{had}$ an accidental blockage of the canal with $169 \mathrm{~L}$ carbide bur in the apical third of canal. The fractured fragment was retrieved with file braiding technique.

Conclusion: This case series has described conservative and simple techniques for removal of fractured instruments from the root canals of an anterior and posterior tooth.
\end{abstract}

Keywords: 169L tungsten carbide bur, Case series, Distal canal, File braiding technique, Instrument separation, Magnification, ProTaper gold F2, Ultrasonics.

Conservative Dentistry and Endodontic Journal (2019): 10.5005/jp-journals-10048-0049

\section{BACKGROUND}

Accidental breakage of instruments can occur during root canal treatment, the management of which decides the success of the treatment. latrogenic inclusion of various objects such as absorbent points, burs, files, glass beads, and amalgam or gold fillings has been reported inside the root canals. ${ }^{1-6}$ Root canals can be blocked by the person himself by inserting metallic objects like pins, needles, or wooden tooth picks. A separated instrument prevents complete debridement and sealing of the root canal system. Every attempt must be made to retrieve the broken instrument. Retrieval can be done manually or with specialized instrument retrieval kits. Manually with chairside techniques such as wire-and-loop method, file-braiding technique, hypodermic needle, and glue technique. Instrument retrieval kits are Masserann kit, Instrument Removal System kit, Terauchi File Retrieval kit, and Canal Finder system. ${ }^{7}$ The use of specialized ultrasonic tips under dental operating microscope enables precise use of ultrasonic, avoiding unnecessary dentin removal thereby increasing the success rate by $67-95 \%{ }^{8}$ Another method for retrieval is electrochemical induced dissolution of fractured instrument. The present case series describes the management of a separated bur head and a rotary file from the root canals of maxillary canine and mandibular second molar, respectively.

\section{Case Description}

\section{Case 1}

A 14-year-old female patient reported to the department of conservative dentistry and endodontics with the complaint of pain in lower right back tooth since 2 days. After clinical and radiographic examination, case was diagnosed as symptomatic irreversible pulpitis with apical periodontitis in relation to 47 (Fig. 1).
${ }^{1-4}$ Department of Conservative Dentistry and Endodontics, Azeezia College of Dental Sciences and Research, Kollam, Kerala, India

Corresponding Author: Sangeetha Saji, Department of Conservative Dentistry and Endodontics, Azeezia College of Dental Sciences and Research, Kollam, Kerala, India, Phone: +91 9633523902, e-mail: sangeetha.saji32@gmail.com

How to cite this article: Saji S, Geetha P, Nair RK, et al. Management of Instrument Separation: A Case Series. Cons Dent Endod J 2019; 4(2):39-43.

Source of support: Nil

Conflict of interest: None

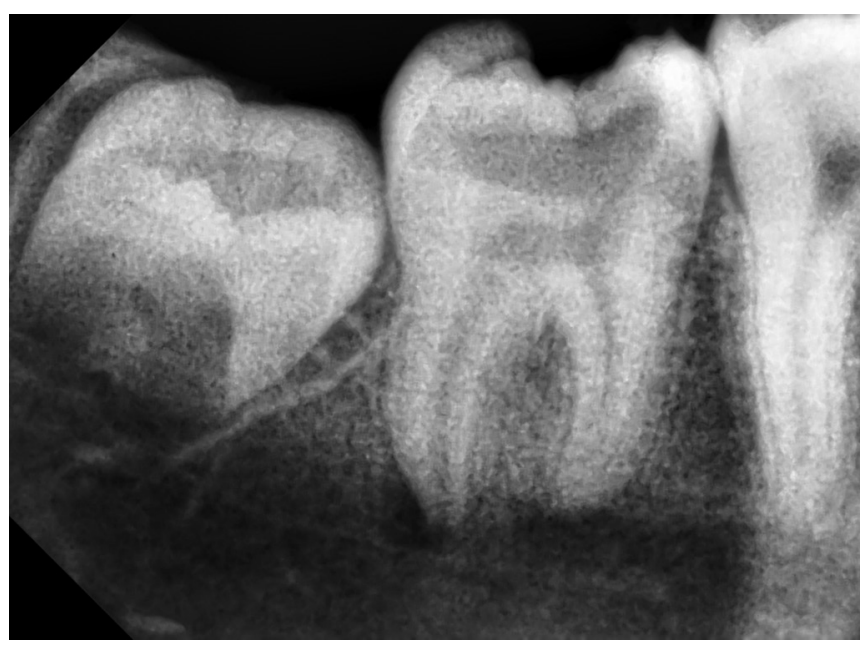

Fig. 1: Preoperative radiograph

o The Author(s). 2019 Open Access This article is distributed under the terms of the Creative Commons Attribution 4.0 International License (https://creativecommons. org/licenses/by-nc/4.0/), which permits unrestricted use, distribution, and non-commercial reproduction in any medium, provided you give appropriate credit to the original author(s) and the source, provide a link to the Creative Commons license, and indicate if changes were made. The Creative Commons Public Domain Dedication waiver (http://creativecommons.org/publicdomain/zero/1.0/) applies to the data made available in this article, unless otherwise stated. 


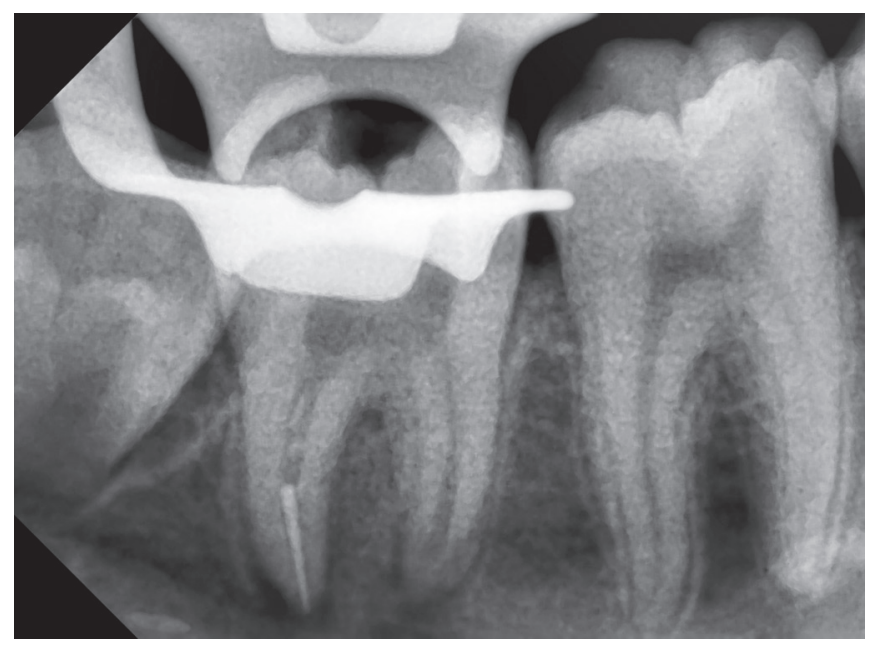

Fig. 2: Fractured F2 in apical third

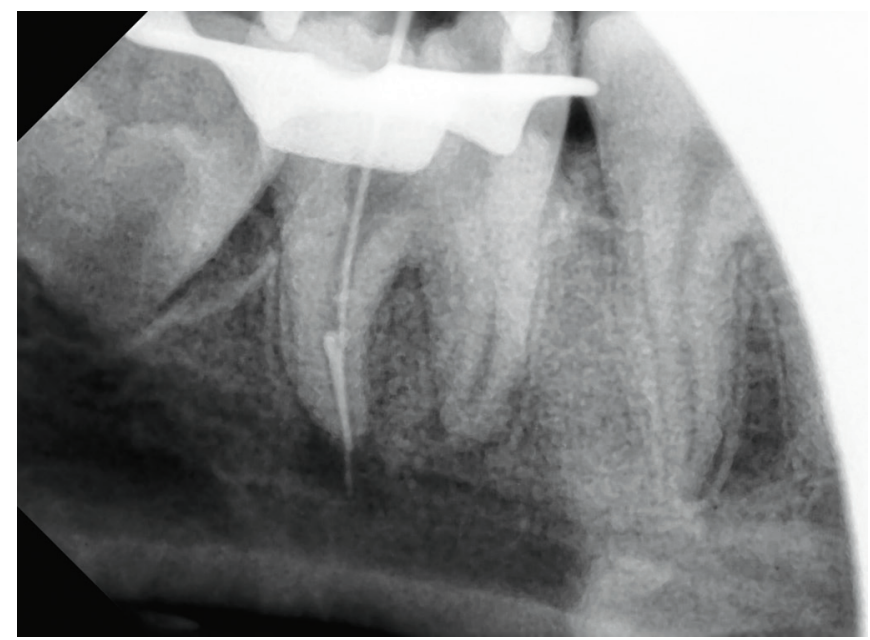

Fig. 4: Bypassed up to no. 20 size K file

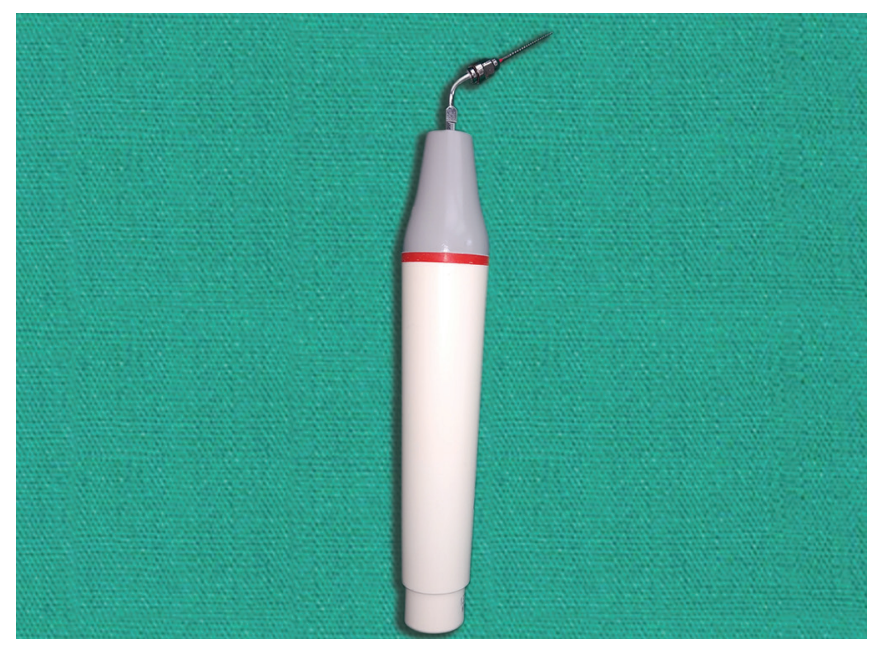

Fig. 6: Ultrasonic handpiece with file attached

Root canal treatment was planned on 47. Access opening and instrumentation was done up to 20 size $\mathrm{K}$ file followed by rotary instrumentation with PROTAPER GOLD rotary files. While instrumenting the distal canal a $5 \mathrm{~mm}$ segment of the rotary file $\mathrm{F} 2$

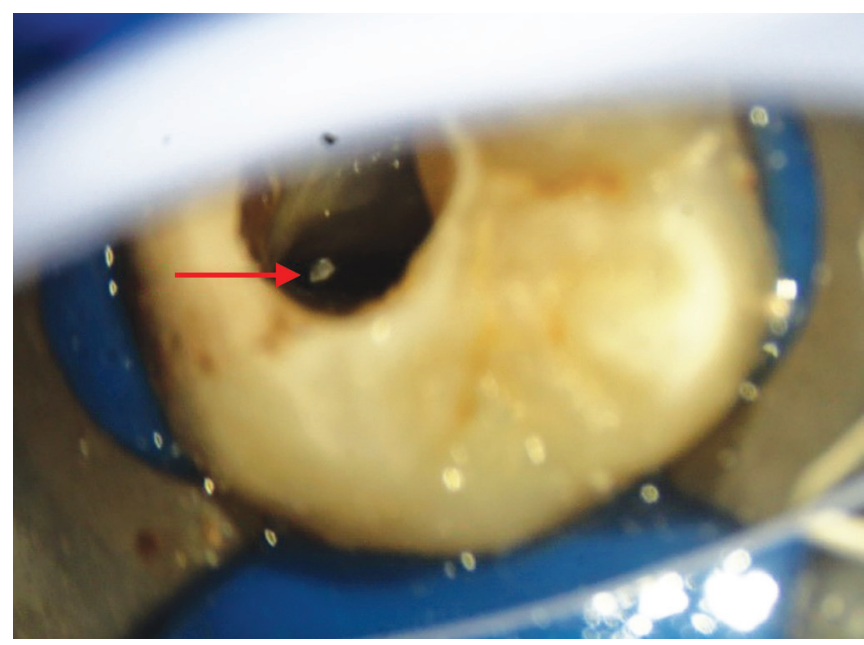

Fig. 3: Microscopic view of fractured file in distal canal marked by red arrow

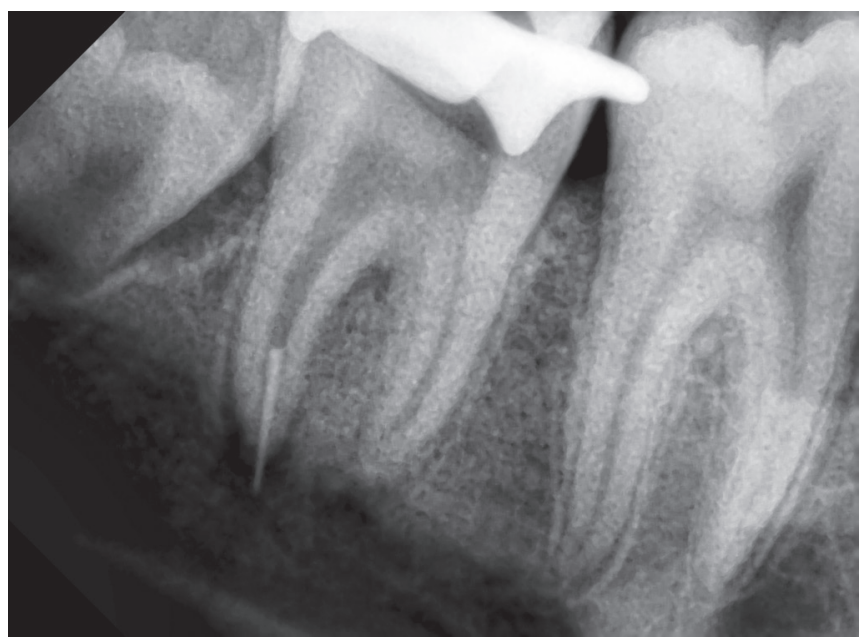

Fig. 5: File pushed beyond apex

got separated. Radiograph revealed that the fractured segment was in the apical third of distal canal of 47 (Fig. 2). The fractured segment was viewed under dental operating microscope (Fig. 3). K files were sequentially used to bypass the separated file (Fig. 4). Attempting to retrieve the segment further pushed it beyond the apex (Fig. 5). The Woodpecker ultrasonic system with ultrasonic U file no. 20 and no. 25 size (Fig. 6) was used at low power setting and made to contact the fractured instrument and vibrate. Ultrasonically activated files with water coolant were used to loosen the fragment from the inner dentin. Intermittent irrigation was done with normal saline. Once the instrument was set loose within the canal, the instrument was flushed out with normal saline. Radiograph was taken to confirm removal of instrument (Figs 7 and 8). Obturation was completed on subsequent appointment (Fig. 9)

\section{Case 2}

A 47-year-old female patient reported to the department of conservative dentistry and endodontics with the complaint of pain in relation to upper front teeth since 2 weeks. On clinical examination, deep dentinal caries was seen on distal aspect of 13 and partially dislodged amalgam restoration with secondary caries in relation to 14 . The tooth 13 had mild tenderness to percussion and had no pain on palpation. On radiographic examination, 


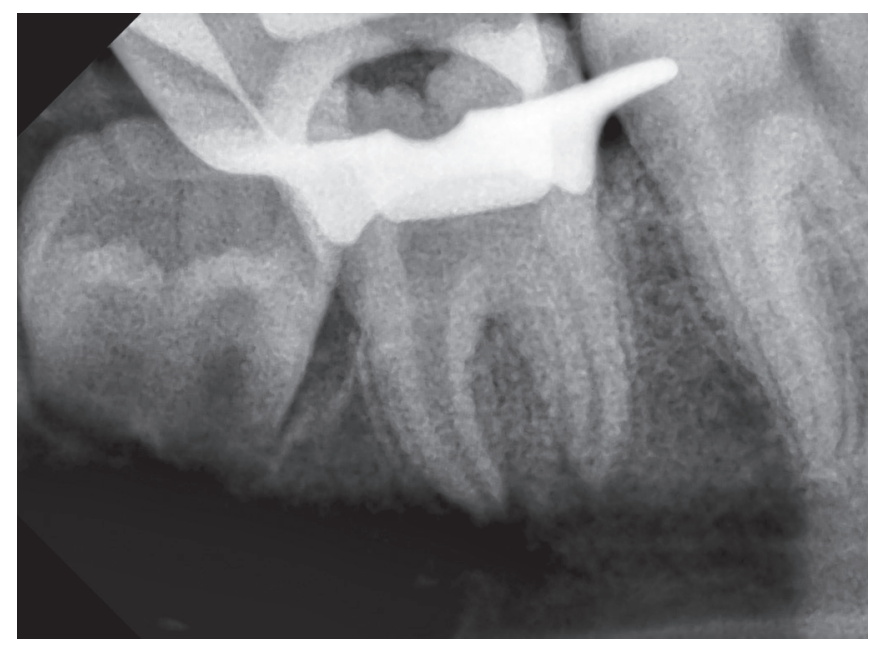

Fig. 7: Radiograph after removal of separated instrument

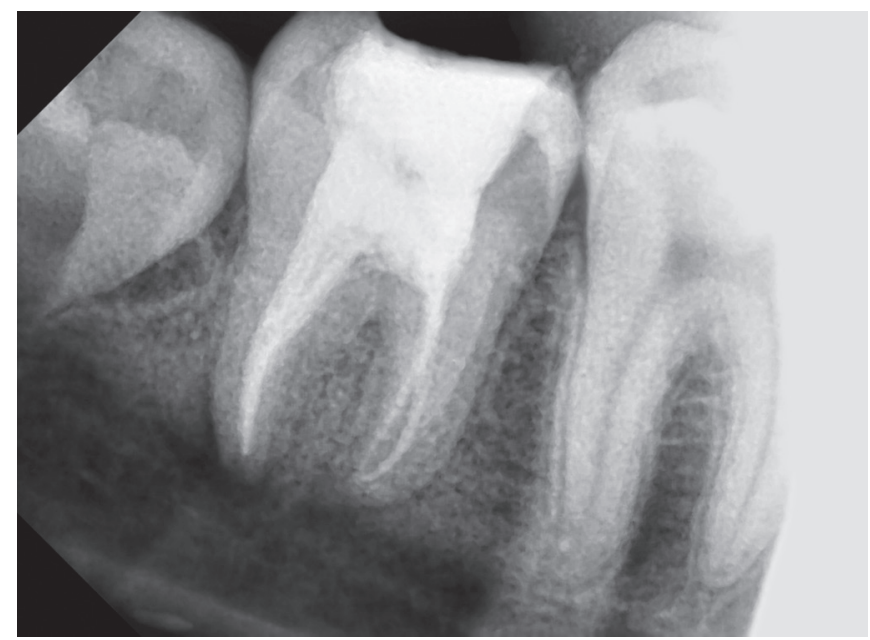

Fig. 9: Postobturation radiograph

radiolucency was seen on distal aspect of 13 suggestive of deep caries, no periapical changes noted (Fig. 10). Case was diagnosed as symptomatic irreversible pulpitis with apical periodontitis in relation to 13. Root canal treatment was planned for 13 and 14 .

On the first visit, root canal treatment was initiated on 13 under local anesthesia and rubber dam isolation, access cavity prepared and biomechanical preparation completed. On second visit, during access cavity refinement there was an accidental breakage of the $169 \mathrm{~L}$ tungsten carbide bur within the tooth. While trying to remove the separated bur, it was pushed further toward the apex. Radiograph revealed that bur was at the junction of middle and apical third of the root canal. The fractured segment in the canal was about $2.5 \mathrm{~mm}$ long (Fig. 11)

Gentle and careful instrumentation enabled the fragment to be bypassed with K-file up to 20 size to the full working length (Fig. 12). Retrieval was tried with indirect ultrasonic vibrations applied to the handle of bypassed K-file, but it failed to deliver the instrument out of the canal. Two new Headstrom files of size 15 and 25 were used to bypass the bur fragment buccally and lingually and were engaged as deep as possible, twisted clockwise using the file braiding technique. Braiding of these files and a short outward pull resulted in the instrument being removed from the canal (Figs 13 and 14). Radiograph was taken to confirm

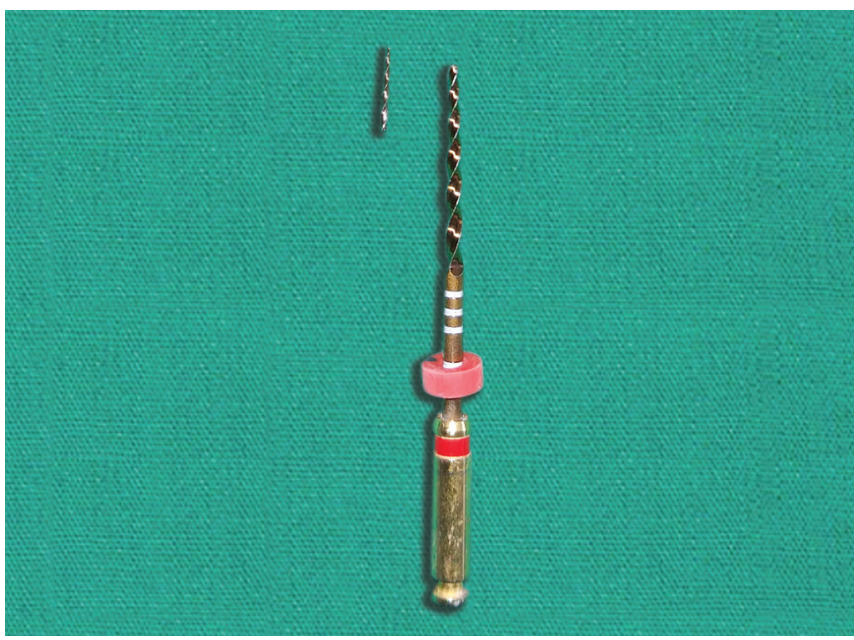

Fig. 8: Fractured file F2 with its fragment

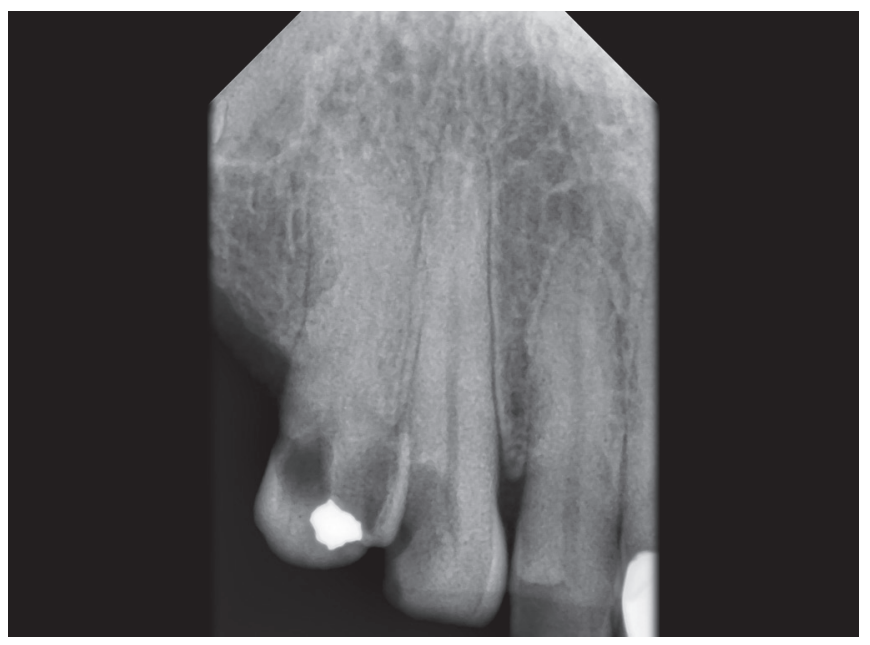

Fig. 10: Preoperative radiograph

the patency of the canal. Cleaning and shaping were performed manually, and obturation was performed with gutta-percha using cold lateral compaction technique and access cavity was restored with resin composite. Root canal treatment of 14 was completed on subsequent appointment (Fig. 15). The patient was asymptomatic during the 6-month follow-up period (Fig. 16). Unfortunately, patient failed to report for further follow-ups.

\section{Discussion}

latrogenic mishaps can occur during root canal treatment either due to anatomical variation of tooth or due to faulty instrumentation technique. ${ }^{9}$ The separation of nickel-titanium rotary instruments was reported to range between $1.3 \%$ and $10 \%$, whereas separation rates of stainless steel instruments reported to range between $0.25 \%$ and $6 \% .{ }^{10-12}$ There are many reasons for separation of rotary files but most common reasons are cyclic fatigue and torsional failure. ${ }^{7,11}$ Separated instrument in the root canal may not directly compromise the prognosis of the tooth. Today, separated instruments can usually be removed due to technological advancements in vision with the help of a dental operating microscope and ultrasonic instrumentation. The use of microscope guides the instrument retrieval and minimizes the damage to the canal dentin. According to Nevares et al., when the separated fragment was visible with a 


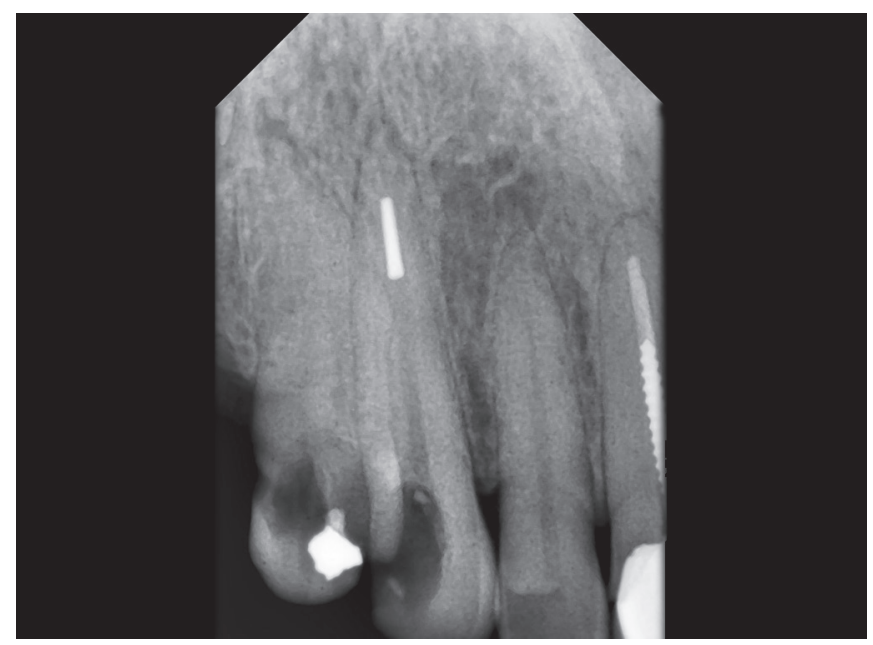

Fig. 11: Separated bur head within the canal

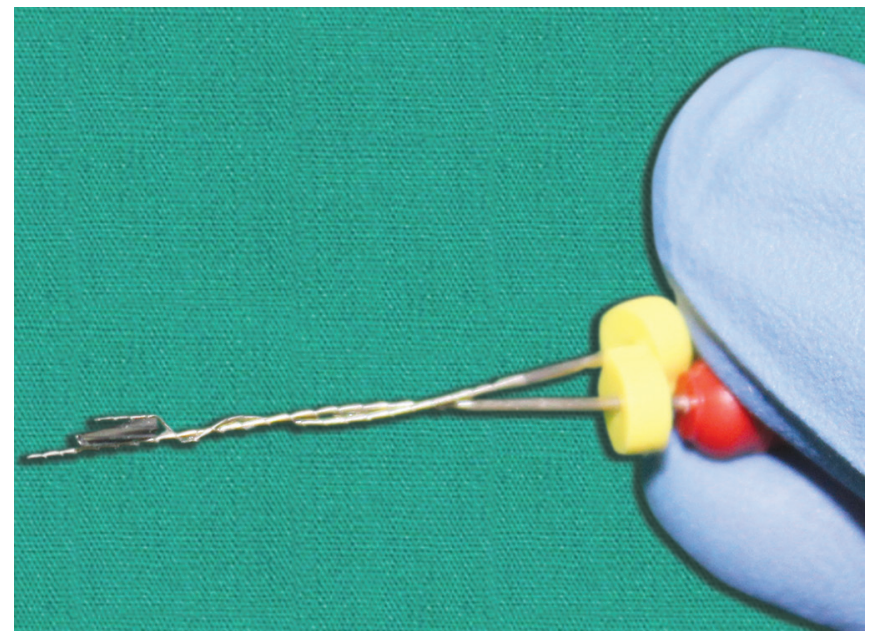

Fig. 13: Braided $\mathrm{H}$-files with fractured bur head

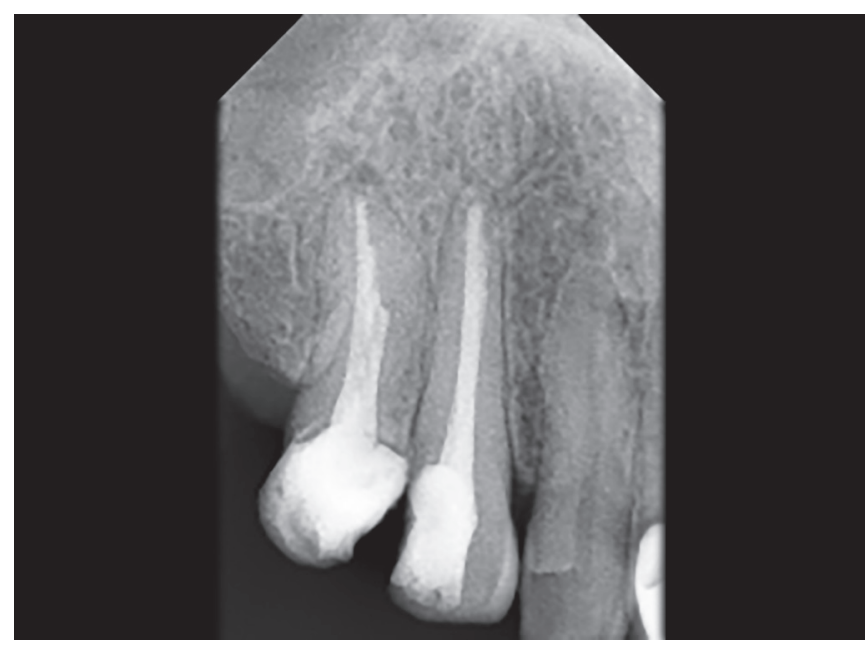

Fig. 15: Postobturation radiograph

microscope, the success rate of retrieval was $85.5 \%$ in comparison with when the fragment was not visible wherein the success rate was $47.7 \% .^{13}$

The use of ultrasonics in endodontics was first described by Richman in 1957. The contra-angled design of ultrasonic tips and

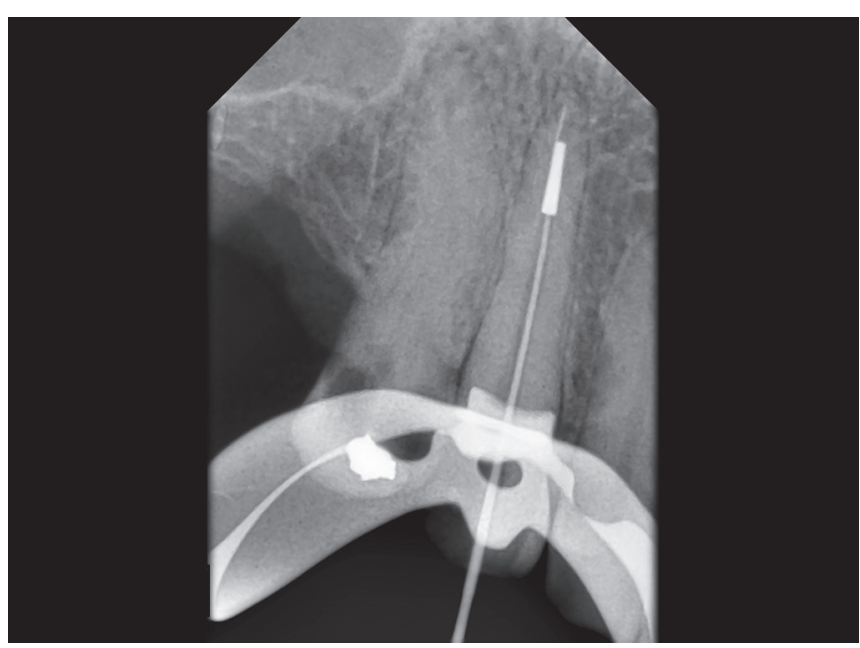

Fig. 12: Bypassed with no. 20 size K-file

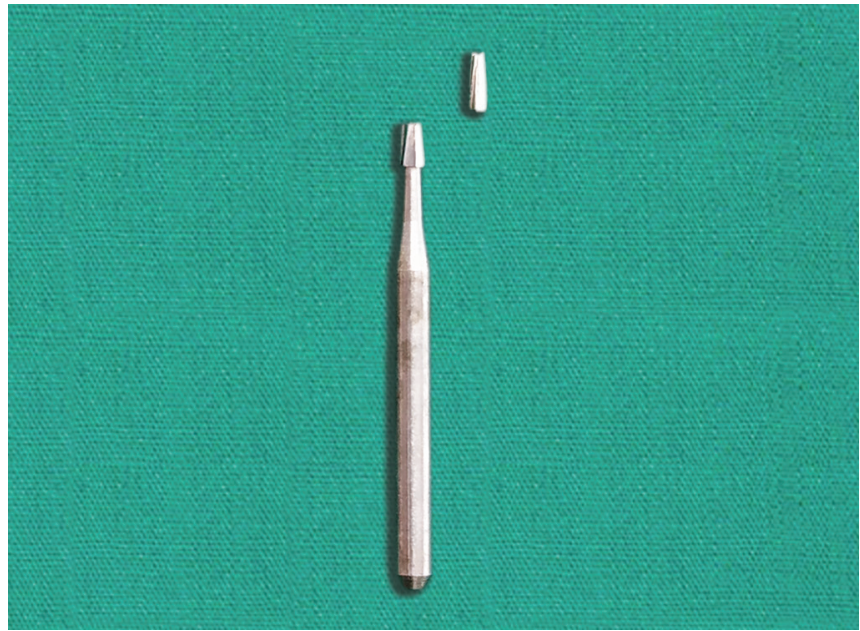

Fig. 14: Fractured bur with its fragment

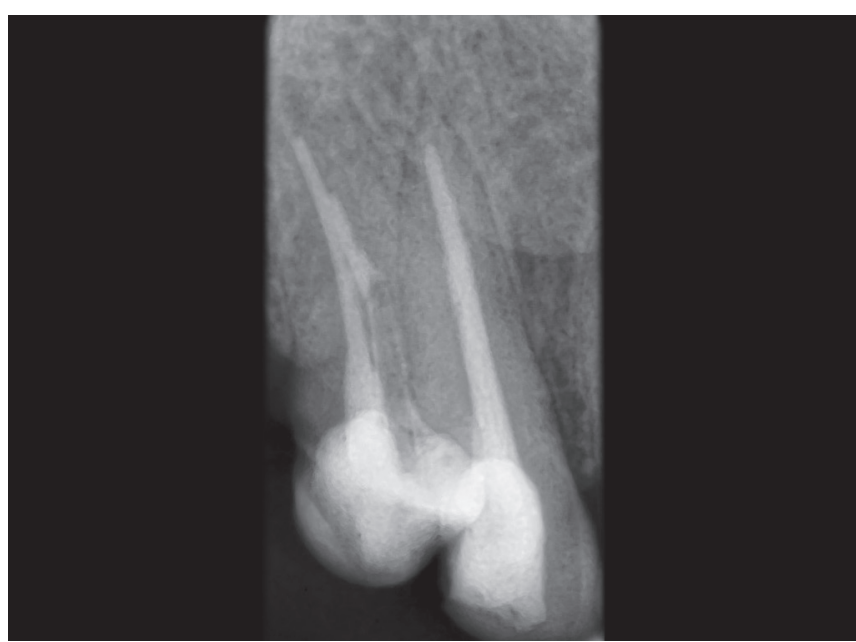

Fig 16: Six months follow-up

availability of different lengths and sizes of ultrasonic files enable its use in deeper parts of the canal. Instrument retrieval kits are available such as Masserann kit, Terauchi file Retrieval kit, and Canal Finder system. However, these devices are very expensive and usually involve removal of a considerable amount of dentin which 
could weaken the roots. The use of specialized ultrasonic tips under dental operating microscope under high-power magnification can overcome the problem of excessive removal of dentin.

Carbide burs have largely replaced stainless steel burs. They are much harder than steel and less subjected to dulling during cutting but it is also more brittle. ${ }^{14}$ Carbide head is attached to a steel shank and neck by soldering, which makes them more prone to fracture. Fracture in bur head can be related to several factors, such as repeated use of the same instrument, and the operator's inexperience. The positive rake angle of carbide burs is attributed to decreased life of the bur. Although Masserann kit has shown successful results for fragment removal, it requires a large loss of root canal dentin. ${ }^{13}$ Thus, it could result in perforation or fracture of narrow roots. ${ }^{4}$ Chemical dissolution of bur is possible using chemical agents like iodine trichloride, nitric acid, hydrochloric acid, and sulfuric acid. These methods may help in achieving intentional corrosion of the metal objects but could be irritant to the tissues. ${ }^{15}$

In the second case, it was possible to bypass the fractured instrument; hence, there was greater chances for retrieval with braiding technique. Braiding is a simple technique that can be used to remove fractured instruments from deeper in the root canal. In file-braiding technique, two or three different sizes of new $\mathrm{H}$-files were gently screwed into the canal alongside of the fragment, wound around each other and withdrawn together with an outward stroke. ${ }^{16}$ The object should be gripped by the files and removed.

There are various factors that may contribute to the successful management of fractured instruments within root canals. The success rate in maxillary teeth is found to be higher than in mandibular teeth. ${ }^{17}$ Studies have shown that NiTi instruments fractured mostly in canals with severe curvature. Location of the fragment in the canal is another factor. Fragments located before the root canal curvature were removed completely. ${ }^{18}$ The length of fragment also tends to affect the success rate. Fragments shorter than $5 \mathrm{~mm}$ present the lowest success rate. ${ }^{19}$ When conservative management of a separated instrument fails and clinical and/ or radiographic follow-up indicates presence of disease, surgical intervention may be warranted if the tooth is to be retained. The broken instrument itself is not a direct cause of treatment failure but rather an indirect one, because it may have prevented adequate cleaning, shaping, and filling of root canal. Therefore, the therapeutic goal is to either retrieve or bypass it in order to get access to the uncleaned portion of the root canal.

\section{Conclusion}

The best antidote for a separated instrument is prevention. However, on occasion of an instrument breakage, it is preferable to remove the fragment and pursue treatment. But in spite of the best existing technologies and techniques, the broken file segment may not be retrieved. In these instances, the instrument may be bypassed. In the presence of clinical symptoms and/or radiographic pathology, surgery or extraction may be the treatment option.

\section{Clinical Significance}

Even with utmost care, instrument separation is unavoidable in clinical practice. There are three options left to the clinician once a separation occurs. They are to bypass, retrieve, or leave the fragment within the canal. Today, separated instruments can be removed due to technological advancements like dental operating microscope and ultrasonic instrumentation.

\section{References}

1. Grossman LI. Endodontic case reports. Den Clin North Am 1974;18(2):509-527.

2. Sternberg RN. Retrieval of broken instrument from root canal. Oral Surg Oral Med Oral Path 1977;44(2):325. DOI: 10.1016/00304220(77)90288-2.

3. Meidinger DL, Kabes BJ. Foreign object removal utilizing the CaviEndo ultrasonic instrument. J Endod 1985;11(7):301-304.DOI: 10.1016/ S0099-2399(85)80161-8.

4. Fors UGH, Berg JO. A method for the removal of broken endodontic instruments from root canals. J Endod 1983;9(4):156-159. DOI: 10.1016/S0099-2399(83)80038-7.

5. Souyave LC, Inglis AT, Alcalay M. Removal of fractured endodontic instruments using ultrasonics. Br Dent JI 1985;159(8):251-253. DOI: 10.1038/sj.bdj.4805695.

6. Feldman G, Solomon C, Notaro P, et al. Retrieving broken endodontic instruments. J Am Dent Asso 1974;88(3):588-591. DOI: 10.14219/jada. archive.1974.0113.

7. Madarati AA, Hunter MJ, Dummer PM. Management of intracanal separated instruments. J Endod 2013;39(5):569-581. DOI: 10.1016/ j.joen.2012.12.033.

8. Fu M, Zhang Z, Hou B. Removal of broken files from root canals by using ultrasonic techniques combined with dental microscope: a retrospective analysis of treatment outcomes. J Endod 2011;37(5): 619-622. DOI: 10.1016/j.joen.2011.02.016.

9. Gambarini G. Cyclic fatigue of ProFile rotary instruments after prolonged clinical use. Int Endod J 2001;34(5):386-389. DOI: 10.1046/j.1365-2591.2001.00259.x.

10. Crump MC, Natkin E. Relationship of broken root canal instruments to endodontic case prognosis: a clinical investigation. J Am Dent Assoc 1970;80(6):1341-1347. DOI: 10.14219/jada.archive.1970. 0259.

11. Al Fouzan KS. Incidence of rotary ProFile instrument fracture and the potential for bypassing in vivo. Int Endod J 2003;36(12):864-867. DOI: 10.1111/j.1365-2591.2003.00733.x.

12. Pettiette MT, Conner D, Trope M. Procedural errors with the use of nickel titanium rotary instruments in undergraduate endodontics. J Endod 2002;28(3):259.

13. Nevares G, Cunha RS, Zuolo ML, et al. Success rates for removing or bypassing fractured instruments: a prospective clinical study. J Endod 2012;38(4):442-444. DOI: 10.1016/j.joen.2011.12.009.

14. Atkinson AS. The significance of blade geometry in the cutting efficiency of tungsten carbide dental burs at ultrahigh speeds. Br Dent J 1983;155(6):187-193. DOI: 10.1038/sj.bdj.4805171.

15. Hulsmann M. Methods for removing metal obstruction from root canal. Endod Dent Traumatol 1993;9(4):223-237. DOI: 10.1111/j.16009657.1993.tb00278.x.

16. Chenail BL, Teplitsky PE. Orthograde ultrasonic retrieval of root canal obstruction. J Endod 1986;13:186-190. DOI: 10.1016/S00992399(87)80138-3.

17. Shen Y, Peng B, Cheung GS. Factors associated with the removal of fractured NiTi instruments from the root canal systems. Oral Surg Oral Med Oral Pathol Oral Radiol Endod 2004;98(5):605-610. DOI: 10.1016/j.tripleo.2004.04.011.

18. Hulsmann M. Removal of silver cones and fractured instruments using canal finder system. J Endod 1990;16(12):596-600. DOI: 10.1016/ S0099-2399(07)80203-2.

19. Hulsmann M, Schinkel I. Influence of several factors on the success or failure of removal of fractured instruments from the root canal. Endod Dent Traumatol 1999;15(6):252-258. DOI: 10.1111/j.1600-9657.1999. tb00783.x. 